\title{
Unveiling the diversity of scholarly debate on living labs: A bibliometric approach
}

\section{Katharina Greve*}

University of Cambridge, The Old Schools, Trinity Lane, Cambridge,

CB2 1TN, United Kingdom.

University of Greenwich, Park Row, SE10 9LS, UK

E-mail: $\underline{\text { kg403@cam.ac.uk }}$

* Corresponding author

\section{Seppo Leminen}

University of South-Eastern Norway, Post office box 235

3603 Kongsberg, Norway

E-mail: seppo.leminen@usn.no

\& Aalto University School of Business, Department of Marketing,

P.O. Box 21230, FI-00076 Aalto, Finland

E-mail: seppo.leminen@aalto.fi

\& Carleton University, Sprott School of Business, 1125 Colonel By

Drive, Ottawa, ON, K1S 5B6, Canada

\section{Riccardo De Vita}

University of Greenwich, Park Row

SE10 9LS, United Kingdom

E-mail: r.devita@gre.ac.uk

\section{Mika Westerlund}

Carleton University, Sprott School of Business, 305 Saint Patrick's Bldg., 1125 Colonel By Drive, Ottawa, ON, K1S 5B6, Canada

E-mail: mika.westerlund@ carleton.ca

\begin{abstract}
Living labs (LLs) are becoming an increasingly popular approach to engage in open innovation. Although applications and influence of LLs have grown rapidly over the last decade, the landscape of LL research remains largely unclear and underexplored. Hence, there is an urgent need to develop a consolidated understanding of this research field and to detect potential areas of fragmentation and isolation. Through a systematic review of the scholarly literature on LLs, this study applies bibliometric methods on a dataset of 411 journal articles. The results of this study reveal the diverse and fragmented nature of the LL field, with contributions spanning across different disciplines and application domains. Despite such fragmentation, some clusters of scholars and publications are identified as well as influential contributions. Given the nascent state of the literature, the role of special issues in shaping the evolution of the LL debate is prominent. This study provides a map to practitioners to investigate and
\end{abstract}


learn from the application of LLs in diverse fields. This aspect is particularly important in light of current events, which stress the key role of open and collaborative approaches to innovation, making the use of LLs increasingly relevant for governments, companies, public organisations and individuals.

Keywords: living lab; innovation; bibliometric analysis; bibliometric methods; co-citation analysis; innovation management; literature review; network analysis; open innovation

\section{Introduction}

Living labs (LLs) are becoming an increasingly popular approach to engage in open innovation, as they offer access to external knowledge and expertise. LLs provide a collaborative platform for the creation, prototyping, validating, and testing of new technologies, products, services and systems (Westerlund and Leminen, 2011). Facilitating the interaction between users, private and public organisations and research institutions, LLs offer the opportunity to co-create new products or services in physical or virtual settings closely replicating a realistic use situation (Bergvall-Kåreborn, Holst and Ståhlbröst, 2009; Leminen, Westerlund and Nyström, 2012). Following an open innovation model, organisations use LLs to reach beyond their own boundaries to integrate users in the co-creation process. This allows them to uncover their customers' latent needs and enables them to benefit from unforeseen outcomes (Leminen and Westerlund, 2012).

A growing number of organisations that consider themselves as 'living labs' have emerged all over the world during the last two decades. Simultaneously, national, regional, and international bodies such as the European Union started to introduce LLs into their set of innovation tools. Despite some significant advancements in the field, scholars have recently highlighted the need for more comprehensive reviews of the nascent LL literature (e.g. McLoughlin et al., 2018; Westerlund, Leminen and Rajahonka, 2018; Hossain, Leminen and Westerlund, 2019).

To address this gap, this study offers a novel and systematic analysis of the structure and content of LL research. The objective of the paper is to map the landscape of LL research and to detect potential areas of fragmentation and isolation in the LL field through the following research questions: (i) What are the intellectual streams underpinning LLs? (ii) How do such intellectual streams and key concepts inform future research and practice? The main contribution of this article lies in the identification of the foundations of current LL literature and the structure of the ongoing academic debate. Doing so, the paper uncovers those theories and concepts, which can bridge topics currently studied in isolation in order to advance LL research. The study shows the growth of the research field, but also the importance of developing a cohesive community of scholars to promote its expansion consistently. The recommendations of this study emerge from a systematic and comprehensive analysis employing bibliometric methods, including co-citation, coauthorship and keyword co-occurrence analysis, on 411 core journal articles published on LLs.

Following the introduction, the evolution of LL research is discussed, highlighting features and insights of existing LL reviews. The third section outlines the sample selection strategy and introduces co-citation, co-authorship and keyword co-occurrence analysis. The findings are presented in section four. The section identifies the intellectual streams 
and core concepts underpinning LL research, and outlines potential opportunities to advance the understanding of LLs. Finally, the article concludes with implications for theory, contributions to practice and recommendations for future research directions. Also, the study's limitations are discussed.

\section{The Evolution of LL Research}

The roots of the term "living laboratory" can be traced back to Knight (1749), who considered it as elements and conditions of a human body and an environment of an experiment. However, Professor William J. Mitchell from MIT has often been acknowledged as the father of LLs, as his research started one of the very early LL activities in Europe (Leminen and Westerlund, 2019). Mitchell used the term LL in relation to the observation of regular home life activities taking place in a real home (Mitchell, 2003). With the aim to obtain more accurate and realistic user information by gathering long-term data and conducting observations of everyday activities, a LL was viewed as an extension of laboratory experiments. In this view, 'houses of the future', demo-homes as well as home labs are considered LLs. In this "American", or original, version of LLs, users are mainly passive research subjects, with no direct involvement in the development of products or services (Schuurman et al., 2011).

In contrast, Schuurman et al. (2011) describe European LLs as oftentimes short-term and small-scale co-creation projects that are carried out in real-life settings to study users' everyday habits. Some other studies view LLs as a movement or continuum of activities encompassing longitudinal needs of multiple stakeholders (Leminen and Westerlund, 2019; Leminen, Nyström and Westerlund, 2019). Five basic elements that reflect the goals and characteristics of European LLs are highlighted by Ballon and Schuurman (2015). These five elements include active user involvement, a real-life environment, the participation of multiple stakeholders and a multi-method approach, as well as co-creation. In 2006, the European LL movement gained particular traction, also thanks to several policy measures by the European Union (EU) (Dutilleul, Birrer and Mensink, 2010), which also led to the establishment of the European Network of Living Labs (ENoLL).

LLs have helped establishing ecosystems of innovation that offer advantages to both private and public organisations (Gascó, 2017) by integrating a wide range of expertise (Abowd, 1999) and stakeholders (Leminen, Rajahonka and Westerlund, 2017). They are seen as part of a wider re-organisation of the relationship between producers and users and as a novel instrument, methodology and design for practitioners to manage contemporary challenges and needs (e.g. Voytenko et al., 2016; Rodrigues and Franco, 2018). By emphasising the appropriation phase of the innovation process, LLs address the limitations of linear and design-centred innovation models (Williams, Stewart and Slack, 2005).

LLs are conceptualised in different ways and along different dimensions within the broader innovation management literature. For example, Sanders and Stappers (2008) suggest that LLs belong to the human-centred innovation approach. Almirall et al. (2012), on the other hand, position them with respect to other user-contributed innovation methodologies, drawing attention to two dimensions. The first dimension takes into account the participation of users in the co-creation process identifying diverse practices. Approaches such as ergonomics, human factors, or applied ethnography see users as subjects of observation. User-innovation methodologies such as lead users or open source communities, instead, consider users are co-creators. The second dimension Almirall et al. 
(2012) examined is the setting in which user participation takes place, having lab-like environments at one extreme and real-life settings at the other. Depending on the extent of user involvement in the innovation process, the study presents the illustrated methodologies in four categories. Based on to the scholars' interpretation, LLs are positioned among user driven methodologies together with open source and lead users; in this grouping, the innovation process is driven by users. Focusing on prevailing European LL approaches, Almirall et al. (2012) put forward four propositions. Firstly, to acquire market knowledge, or more specific domain-based knowledge, users are involved at the start of the innovation journey. Secondly, the significance of real-life settings as the locus of study is highlighted. Thirdly, the presence of public-private-partnerships (PPPs) is identified as another distinctive characteristic of LL methodologies. Fourthly, LLs benefit from PPPs as they generate an initial demand, and also frequently engage with other stakeholders, including for example small and medium-sized firms, to ease entry in multistakeholder or highly regulated environments.

LLs are also compared to open innovation and social computing. Pascu and van Lieshout (2009) emphasise that they all stress the user role in the innovation process. By facilitating the opening of new geographical markets, LLs create an opportunity to study new products and services and the growth of new service ecosystems. According to the authors, active end-user involvement in the online communities' development process can be empowered through LLs. LLs can be used indeed to reach beyond the "launch-andlearn" approach in online social communities (Pascu and van Lieshout , 2009).

\section{Existing Reviews on LLs}

Due to their difficult conceptualisation, the essence of LLs remains largely unclear and underexplored (Hossain, Leminen and Westerlund, 2019), making it imperative for researchers and practitioners alike to develop a holistic understanding of the LL field. This task is however particularly complex in fields, such as in the case of LLs, where the literature is recent, quickly expanding and containing competing definitions (Di Stefano, Peteraf and Verona, 2010). Although comprehensive systematic literature reviews on LLs are limited, they provide valuable insights into different facets of LL research. A summary of existing reviews of LL literature is provided in Table 1. 
Table 1 Existing Literature Reviews on Living Labs

\begin{tabular}{|c|c|c|c|c|c|c|c|}
\hline Reference & Objectives & Papers & Period & Discipline & Focus & Approach & Documents included \\
\hline Følstad (2008) & $\begin{array}{l}\text { (1) map out the purposes for } \\
\text { which LLs have been } \\
\text { established in the ICT field } \\
\text { (2) investigate how LLs are } \\
\text { deployed with regard to } \\
\text { processes and methods } \\
\text { (3) investigate the theoretical } \\
\text { foundations of LLs }\end{array}$ & 32 & $\begin{array}{l}\text { Until } \\
05 / 2007\end{array}$ & $\begin{array}{l}\text { No specific } \\
\text { criteria } \\
\text { identified }\end{array}$ & ICT & $\begin{array}{l}\text { Thematic } \\
\text { analysis }\end{array}$ & $\begin{array}{l}\text { Workshop papers, } \\
\text { conference articles, } \\
\text { journal papers, white } \\
\text { paper, licentiate } \\
\text { thesis, book chapter }\end{array}$ \\
\hline Franz (2015) & $\begin{array}{l}\text { (1) examine the possibilities } \\
\text { and limitations of using } \\
\text { LLs in urban research } \\
\text { (2) identify current approaches } \\
\text { and gaps in LL concepts }\end{array}$ & NA & NA & $\begin{array}{l}\text { No specific } \\
\text { criteria } \\
\text { identified }\end{array}$ & Urban LLs & $\begin{array}{l}\text { Literature } \\
\text { review } \\
\text { integrated } \\
\text { with practical } \\
\text { experiences } \\
\text { of LLs }\end{array}$ & NA \\
\hline $\begin{array}{l}\text { Schuurman, } \\
\text { Lieven De } \\
\text { Marez and } \\
\text { Pieter Ballon } \\
\text { (2015) }\end{array}$ & $\begin{array}{l}\text { (1) identify the main } \\
\text { perspectives and } \\
\text { viewpoints on LLs } \\
\text { (2) understand how they have } \\
\text { been embedded within the } \\
\text { more established } \\
\text { innovation theories }\end{array}$ & 45 & $\begin{array}{l}\text { Until } \\
10 / 2014\end{array}$ & $\begin{array}{l}\text { No specific } \\
\text { criteria } \\
\text { identified }\end{array}$ & NA & $\begin{array}{l}\text { Thematic } \\
\text { analysis }\end{array}$ & $\begin{array}{l}45 \text { most cited journal } \\
\text { articles and } \\
\text { conference papers } \\
\text { reviewed }\end{array}$ \\
\hline $\begin{array}{l}\text { Leminen and } \\
\text { Westerlund } \\
\text { (2016) }\end{array}$ & $\begin{array}{l}\text { (1) investigate main research } \\
\text { avenues of research on LLs } \\
\text { (2) reveal the common } \\
\text { assumptions among the } \\
\text { distinct avenues }\end{array}$ & 195 & $\begin{array}{l}\text { Until } \\
03 / 2015\end{array}$ & $\begin{array}{l}\text { No specific } \\
\text { criteria } \\
\text { identified }\end{array}$ & NA & $\begin{array}{l}\text { Thematic } \\
\text { analysis }\end{array}$ & $\begin{array}{l}\text { Journal articles, } \\
\text { conference papers, } \\
\text { workshops papers, } \\
\text { working papers and } \\
\text { white papers }\end{array}$ \\
\hline
\end{tabular}




\begin{tabular}{|c|c|c|c|c|c|c|c|}
\hline $\begin{array}{l}\text { McLoughlin et } \\
\text { al. (2018) }\end{array}$ & $\begin{array}{l}\text { (1) understand how LLs as a } \\
\text { concept and research } \\
\text { approach have developed, } \\
\text { proliferated and influenced } \\
\text { scholarly research }\end{array}$ & 169 & $\begin{array}{l}\text { Until } \\
02 / 2017\end{array}$ & $\begin{array}{l}\text { No specific } \\
\text { criteria } \\
\text { identified }\end{array}$ & NA & $\begin{array}{l}\text { Bibliometric } \\
\text { methods }\end{array}$ & $\begin{array}{l}169 \text { initial peer } \\
\text { reviewed conference } \\
\text { papers and articles, } \\
\text { integrated with } \\
\text { additional sources }\end{array}$ \\
\hline $\begin{array}{l}\text { Westerlund, } \\
\text { Leminen and } \\
\text { Rajahonka } \\
\text { (2018) }\end{array}$ & $\begin{array}{l}\text { (1) understand how the } \\
\text { phenomenon of LLs has } \\
\text { been approached in the } \\
\text { innovation management } \\
\text { literature }\end{array}$ & 86 & $\begin{array}{l}10 / 2011- \\
10 / 2017\end{array}$ & NA & NA & $\begin{array}{l}\text { Topic } \\
\text { modelling }\end{array}$ & $\begin{array}{l}86 \text { articles published } \\
\text { in Technology } \\
\text { Innovation } \\
\text { Management Review }\end{array}$ \\
\hline $\begin{array}{l}\text { Leminen and } \\
\text { Westerlund } \\
\text { (2019) }\end{array}$ & $\begin{array}{l}\text { (1) understand the emergence } \\
\text { and early development of } \\
\text { the LLs movement }\end{array}$ & 21 & 1990-2007 & $\begin{array}{l}\text { No specific } \\
\text { criteria } \\
\text { identified }\end{array}$ & NA & $\begin{array}{l}\text { Longitudinal } \\
\text { thematic } \\
\text { analysis }\end{array}$ & $\begin{array}{l}\text { Journal articles, } \\
\text { conference papers, } \\
\text { workshops papers, } \\
\text { working papers, white } \\
\text { papers }\end{array}$ \\
\hline $\begin{array}{l}\text { Dekker, Franco } \\
\text { Contreras and } \\
\text { Meijer (2019) }\end{array}$ & $\begin{array}{l}\text { (1) evaluate the relevance of } \\
\text { the LL approach as a } \\
\text { research and design } \\
\text { methodology for public } \\
\text { administration research }\end{array}$ & 84 & $\begin{array}{l}2000- \\
05 / 2017\end{array}$ & Social science & $\begin{array}{l}\text { Public } \\
\text { administration }\end{array}$ & $\begin{array}{l}\text { Qualitative } \\
\text { meta- } \\
\text { synthesis }\end{array}$ & Journal articles \\
\hline $\begin{array}{l}\text { Hossain, } \\
\text { Leminen and } \\
\text { Westerlund, } \\
\text { (2019) }\end{array}$ & $\begin{array}{l}\text { (1) identify key LL } \\
\text { characteristics } \\
\text { (2) understand the link } \\
\text { between LLs and } \\
\text { sustainable development } \\
\text { (3) reveal essential future } \\
\text { research needs suggested in } \\
\text { the literature offer a robust } \\
\text { foundation to propose an } \\
\text { agenda for future research }\end{array}$ & 114 & 2006 & $\begin{array}{l}\text { Innovation } \\
\text { management, } \\
\text { business, } \\
\text { engineering, } \\
\text { computer and } \\
\text { information } \\
\text { science }\end{array}$ & NA & $\begin{array}{l}\text { Thematic } \\
\text { analysis }\end{array}$ & $\begin{array}{l}\text { Journal articles, } \\
\text { proceedings articles, } \\
\text { filtered by citations } \\
\text { received }\end{array}$ \\
\hline
\end{tabular}


As one of the first studies reviewing the literature in this field, Følstad, (2008) analyses 32 early papers on LLs to identify their theoretical foundations, processes, methods and perspectives. Franz (2015), on the other hand, mainly focuses on the applicability of LLs in urban research. After reviewing 45 of the most cited papers in the field, Schuurman, De Marez and Ballon (2015) conclude that practice-based research is much further developed in contrast to the theoretical side, which remains at a nascent stage. Leminen and Westerlund (2016) discuss eight major research avenues that scholars in the field have taken to understand LLs. These include viewing a LL as (1) a system, an ecosystem, or a network, (2) a combined approach, (3) a context or an environment, (4) a method, methodology, or approach, (5) an enhancement or implementation of public and user involvement, (6) a development project for products, services, or systems, (7) an innovation management tool, and (8) a business activity and operational mode. Their integrative framework positions these perspectives as distinct research avenues. The scholars conclude that the majority of LL researchers share the view that LLs are grounded in real-life environments with a strong focus on the key role of users.

Differently to previous thematic reviews, McLoughlin et al. (2018) employ bibliometric methods to analyse 169 articles. The study investigates how LLs as a concept and research approach have developed, proliferated and influenced scholarly research. The scholars suggest establishing links between Action Design Research (ADR) and LL research, as well as paying closer attention to utilising existing Information Systems theory in order to advance LL research. Instead, Westerlund, Leminen and Rajahonka (2018) observe the development of the LL phenomenon in context of innovation management literature. The scholars use topic modelling on a set of 86 publications on LLs and categorise research approaches within seven broad topics. These include (1) design, (2) ecosystem, (3) city, (4) university, (5) innovation, (6) user, and (7) LL. The study is limited to articles published in Technology Innovation Management Review (TIM Review). Leminen and Westerlund (2019), meanwhile, offer a review of 21 articles to provide an understanding of the emergence of the LL movement. Dekker, Franco Contreras and Meijer, (2019) systematically review applications of LLs in social sciences and evaluate the relevance of the LL approach for public administration research. The study is based on 84 articles and concludes with a call for a "common definition, robust methods and normative questions" (Dekker, Franco Contreras and Meijer, 2019, p. 9). Taking a different perspective, Hossain, Leminen and Westerlund (2019) offer a systematic literature review of 114 scholarly articles about LLs and discuss them thematically. The authors place particular emphasis on the role of LLs in sustainable development.

Although the aforementioned studies enrich our understanding of LLs from different perspectives, scholars acknowledge that LLs are still under-researched, and a theoretical as well as a methodological gap exists (e.g. Ballon and Schuurman, 2015). For this reason, prior research has consistently called for a more comprehensive review of the nascent literature on LLs (e.g. Ballon, Van Hoed and Schuurman, 2018; McLoughlin et al., 2018; Westerlund, Leminen and Rajahonka, 2018; Hossain, Leminen and Westerlund, 2019). To address this gap in the literature and to complement existing reviews, differently to previous research (e.g. Dekker, Franco Contreras and Meijer, 2019; Hossain, Leminen and Westerlund, 2019), our study is not limited by domains or disciplines, but rather aims to deliver a comprehensive and cross-disciplinary perspective on the structure, concepts, and theoretical foundations of the subject. In contrast to previous research (e.g. Følstad, 2008; Schuurman, Lieven De Marez and Pieter Ballon, 2015; Leminen and Westerlund, 2016, 2019), this study focuses only on peer-reviewed journal articles. Furthermore, from a 
methodological standpoint, this paper enriches current research by applying bibliometric methods to identify key concepts underpinning LLs research (Randhawa, Wilden and Hohberger, 2016).

\section{Methodology}

\section{Sample Selection}

This study adopts a systematic process to arrive at the final sample of 411 focal articles. The database Web of Science (WoS) was selected to retrieve articles for the study due to its wide coverage. Differently to other databases such as Scopus, WoS includes articles published by Technology Innovation Management Review (TIM Review) which has published the largest number of special issues and articles on LLs (Westerlund, Leminen and Rajahonka, 2018). Furthermore, WoS has already been used to map similar domains, such as open innovation (Dahlander and Gann, 2010) and technology business incubation (Mian, Lamine and Fayolle, 2016).

The following steps were taken in order to generate the sample of articles studied. Firstly, specific search criteria were determined to ensure that all variations of the LL notion were captured. For this reason, synonymous terms, such as living lab, living laboratory, and living labbing were included ("living lab*"). In line with established practice in comparable studies (Randhawa, Wilden and Hohberger, 2016; Hausberg and Korreck, 2020), this study relies only on peer-reviewed journal articles and therefore, books and conference papers are excluded from the sample. As the objective of the paper is to map the overall landscape of LL research and to detect potential areas of fragmentation and isolation in the LL field, articles published in all disciplines were considered. The search was carried out on $4^{\text {th }}$ January 2020 and led to the identification of an initial list of 850 papers. The abstract, title and keywords of these papers were then independently reviewed by two of the authors of the present study to determine their inclusion in the analysis. When the two authors were in disagreement, further discussions took place and, when necessary, articles were referred to a third author for resolution (Belur et al., 2018). The interrater agreement was of $98.9 \%$, with only 9 papers being referred to a third author (Gisev, Bell and Chen, 2013).

As a result of this systematic review, 440 articles were excluded. For example, Autili et al., (2019) use the term "living laboratory" in its metaphorical meaning. Also, results referring to "living laboratory animals" in the context of medical research were excluded (e.g. Bové et al., 2005). Similarly, articles discussing "living labour" were excluded (e.g. Hartmann, 2014). At the end of the process, 411 articles were included in the sample. Such a sample size is comparable to the one used in similar studies (Randhawa, Wilden and Hohberger, 2016). To maximize the sample size and capture studies from different disciplines, articles were searched in all databases available via WoS. However, some specific article information were only available through WoS' Core Collection. As a result, two different databases were created. Database A includes all 411 focal articles, while Database B represent a subset of Database A and includes 297 papers retrieved from the Core Collection in WoS. The two databases are analysed combining different techniques, as detailed in the following section. 


\section{Analysis}

In order to map the structure of the academic debate surrounding LL research, this paper uses bibliometric techniques. A traditional approach in bibliometric studies is the use of co-citation. Here, co-citation analysis is used to detect the intellectual roots of the LL concept, as it focuses on the cited sources of the focal articles. Co-citation analysis establishes connections between two sources if they are cited together by a third source. The more the two sources are cited together, the stronger their connection and the more likely they are to share some ideas. Co-citation analysis has been fruitfully employed in the field of innovation studies (Di Stefano, Gambardella and Verona, 2012) and with specific attention to open innovation (Kovács, Van Looy and Cassiman, 2015; Randhawa, Wilden and Hohberger, 2016). To perform co-citation analysis, a square co-citation matrix is created. In the matrix, the intersection of row $i$ with column $j$ identifies how often document $i$ and document $j$ are cited together by a third source. Such a matrix is then used to produce a co-citation network, which is visualised through Social Network Analysis (SNA) software (Huisman and van Duijn, 2011). Particularly relevant to this study, is the possibility to measure and visualise the proximity of different citations, so that to identify clusters of citations representing different theoretical roots of current LL research.

Nonetheless, focusing merely on co-citations presents some limitations which are particularly important in the context of this paper. While sources can be assumed to be related to a specific concept, the presence per se of a source in text does not necessarily mean the concept is discussed or extensively used. Furthermore, sources can appear together in a document even if not strictly related. To address such shortcomings, a number of additional analysis are employed. Firstly, a network based on keyword co-occurrence is built. Keywords are indeed useful to capture the key concepts of a paper and therefore can provide a more precise indication of its focus and of potential research trends (Dotsika and Watkins, 2017). Secondly, considering the apparent fragmentation of the LL research field, it is also important to consider networks directly involving scholars. Consistently with the view of Huang and Chang (2011), the integration of an analysis of authorship and citation is deemed to be useful in this context, given the objective to investigate the interdisciplinary nature of LL studies. While analysing citations allows the exploration of the origins of the LL debate, co-authorship analysis is useful to map collaboration between scholars (Huang and Chang, 2011). Following a process similar to the one described above for co-citation, two additional matrices are created: one connecting author keywords appearing in the same article (Figure 3), and another one connecting scholars co-authoring a paper (Figure 2). The resulting matrices have been analysed through the software Ucinet 6 (Borgatti, Everett and Freeman, 2002) and VOSviewer (van Eck and Waltman, 2010).

\section{Findings}

The 411 focal articles were published between 1991 and 2020. Both attention to the field (number of articles directly related to LLs) and its influence (number of articles that cite LLs articles) have grown rapidly over the last decade and more specifically during the last five years. Indeed, most of the publications are very recent, with more than half of the articles being published since 2016. This result highlights once more the vitality of the LL research field, as well as illustrates that the body of literature is rapidly growing and evolving, justifying a systematic review of the field (Figure 1). While the publications are strongly concentrated from a temporal point of view, the same may not be said about the 
main sources. One specific journal attracts a relatively large share of publications (Technology Innovation Management Review: 60 articles), but otherwise the articles are published hither and thither. In fact, only 11 journals are represented five times or more in the dataset (Table 2). In total, these 11 journals capture 125 (30.4\%) articles, confirming the fragmentation of the field, especially considering the fact that such journals cover a wide range of subjects (e.g. entrepreneurship, urban planning, and education). High impact journals publishing LL research include, but are not limited to, Research Policy (e.g. Engels, Wentland and Pfotenhauer, 2019), $R \& D$ Management (e.g. De Silva and Wright, 2019), Industrial Marketing Management (e.g. Nyström et al., 2014), and Journal Of Cleaner Production (e.g. Voytenko et al., 2016; Rodrigues and Franco, 2018).

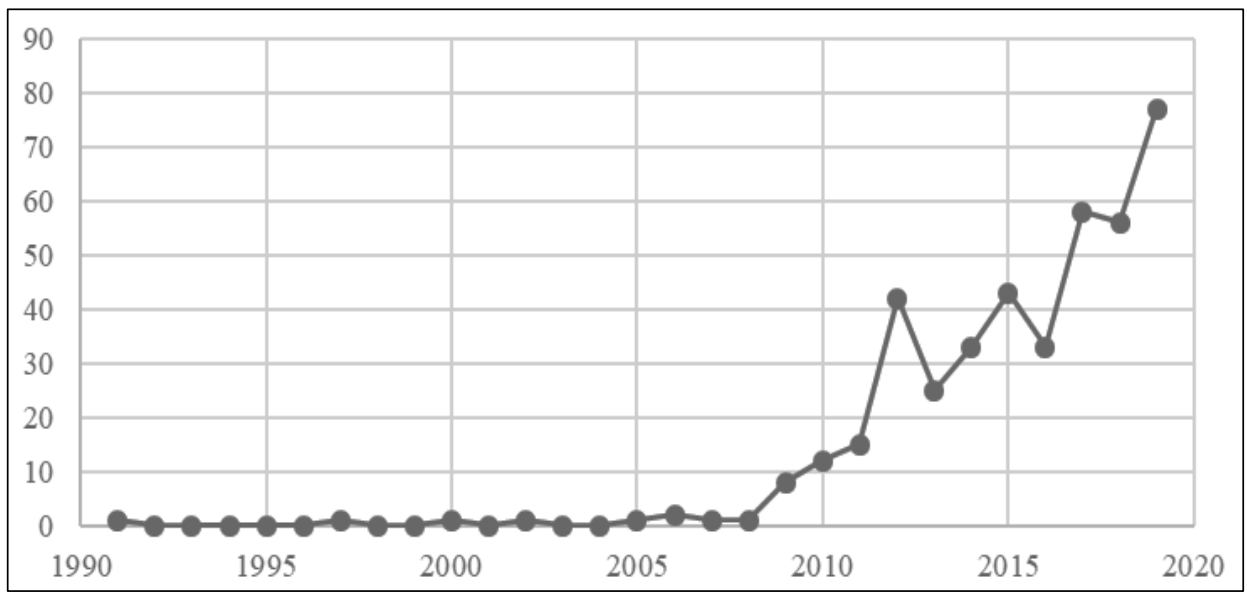

Figure 1 Number of publications by year

Table 2 Journals with at least 5 publications on LLs

\begin{tabular}{ll}
\hline Journal & Number of publications on LLs \\
\hline Technology Innovation Management Review & 60 \\
Sustainability & 12 \\
Info & 8 \\
Journal of Cleaner Production & 7 \\
International Journal of Product Development & 7 \\
IOP Conference Series: Earth and Environmental Science & 6 \\
Sensors & 5 \\
IEEE Pervasive Computing & 5 \\
Electronic Journal of Information Systems in Developing & 5 \\
Countries & \\
Energy Research \& Social Science & 5 \\
Journal of the Knowledge Economy & 5 \\
\hline
\end{tabular}


Figure 2 visually represents the outcome of the co-authorship analysis. 1385 individual scholars were identified as contributors to the 411 papers included in Database A. From the figure it is immediate to observe that two publications (Blain et al., 2014; Bousquet et $a l ., 2014)$ are co-authored by a very large number of scholars, and these authors are mostly the same in both publications (see green circle, Figure 2). Interestingly, those authors involved in such a large project have little to no involvement in other LL publications included in Database A. The remaining part of the network is relatively sparse with several authors contributing only to one or a few articles. This further confirms the fragmentation of the field, which, currently seems to be characterised by authors coming from different disciplines and publishing occasionally about LLs.

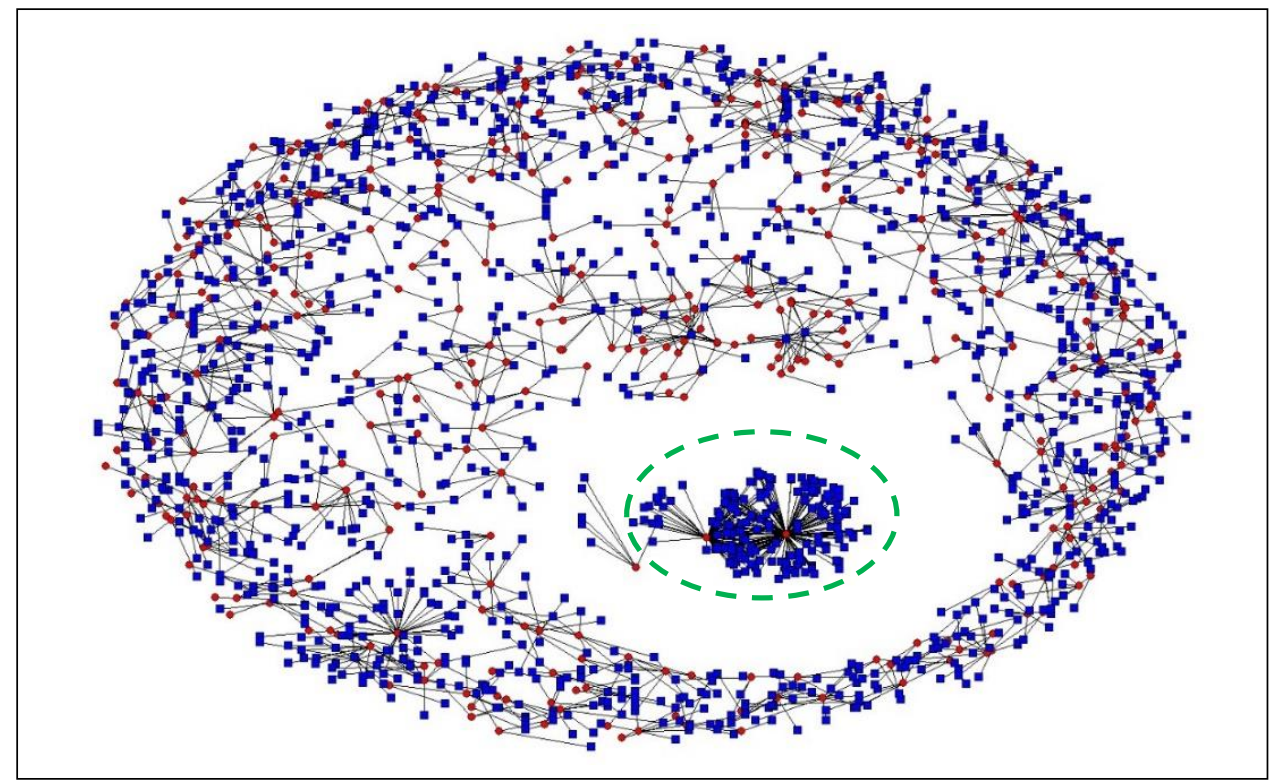

Figure 2 Co-authorship network (papers in red; authors in blue) ${ }^{1}$

Considering the large size of the network and the fragmented nature of the research community, it is of interest to identify those subgroups of authors in direct or indirect connection with each other through a collaborative relationship. Such groups are indeed clusters of scholars who represent subcommunities within the broad LL research field. Table 3 presents the top 10 components in terms of size. A component is a maximal connected subgraph (Wasserman and Faust, 1994). The largest 10 components of the coauthorship network represent 447 authors in total (32.3\%), who study LLs in a wide range of contexts. By definition, components are not connected with each other; the table highlights potential opportunities for collaboration currently unexploited. Components A, $\mathrm{D}$, I and J seem to identify large collaborative teams; they are however the result of outlier papers, with an unusually long list of authors. In such cases, research collaboration around

\footnotetext{
${ }^{1}$ Figure 2 is produced using the software Netdraw (Borgatti et al 2002), which allows the visualization of 2-mode networks. All remaining network visualizations in the paper are obtained using the software VOSviewer (van Eck and Waltman, 2010).
} 
LLs is limited to one or two papers. Indeed, when considering only pairs of co-authors involved in two or more joint publications, only 221 of the 1386 authors (less than 16\%) remain active in the network; the same number drops to 45 authors if the threshold to consider collaboration is increased to a minimum of three papers. In other words, authors seem to only collaborate with each other on a very limited number of occasions.

Table 3 Top 10 components by size - Co-authorship network

\begin{tabular}{|c|c|c|c|}
\hline Component & $\begin{array}{l}\text { Number of } \\
\text { Authors }\end{array}$ & $\begin{array}{l}\text { Proportion } \\
\text { of Authors }\end{array}$ & Description of the component \\
\hline A & 186 & 0.134 & $\begin{array}{l}\text { A very large component of authors, mainly } \\
\text { involved in two papers around the experience of } \\
\text { the MACVIA-LR LL }\end{array}$ \\
\hline B & 61 & 0.044 & $\begin{array}{l}\text { A large group of scholars contributing to research } \\
\text { about LLs in urban context, often with a focus on } \\
\text { sustainability }\end{array}$ \\
\hline $\mathrm{C}$ & 47 & 0.034 & $\begin{array}{l}\text { A large group of scholars contributing to a diverse } \\
\text { set of articles discussing LLs in the broad context } \\
\text { of innovation management at the organisational } \\
\text { and urban level }\end{array}$ \\
\hline D & 35 & 0.025 & $\begin{array}{l}\text { One paper with } 35 \text { co-authors about the use of LL } \\
\text { to investigate avenues to reduce energy } \\
\text { consumption }\end{array}$ \\
\hline $\mathrm{E}$ & 29 & 0.021 & $\begin{array}{l}\text { A cluster of studies where LLs are employed to } \\
\text { investigate the interaction between humans and } \\
\text { ICT }\end{array}$ \\
\hline $\mathrm{F}$ & 21 & 0.015 & $\begin{array}{l}\text { Three papers about the use of LL to promote } \\
\text { inclusivity and rehabilitation }\end{array}$ \\
\hline G & 18 & 0.013 & $\begin{array}{l}\text { Four papers on application of LL to office } \\
\text { environments }\end{array}$ \\
\hline $\mathrm{H}$ & 18 & 0.013 & $\begin{array}{l}\text { Five papers on heterogeneous topics; } \\
\text { collaboration seems to be driven also by } \\
\text { affiliation to the same institutions. }\end{array}$ \\
\hline I & 17 & 0.012 & One paper about the use of a building as a LL \\
\hline $\mathrm{J}$ & 15 & 0.011 & $\begin{array}{l}\text { Two papers discussing a LL approach to explore } \\
\text { human behaviour and interactions by means of } \\
\text { technology }\end{array}$ \\
\hline
\end{tabular}

The limited collaboration characterising the LLs research community and the fragmentation of the field is reinforced when considering the author defined keywords ${ }^{1}$.

\footnotetext{
${ }^{1}$ Keywords were included as presented by the authors. Exceptions were done for the amalgamation of different spelling of the same word (e.g. "co-creation" and "cocreation"), the plural and singular form of the same concept (e.g. "smart city" and "smart cities") and terms with the same meaning (e.g. "innovation tools" and "innovation instruments"). Keywords resulting from such process are identified in the visualisation with an underscore at their beginning. This analysis is performed on the subset of papers identified as Database $\mathrm{B}$ in the earlier sections.
} 
Figure 3 presents the co-occurrence of keywords, showing only 59 keywords occurring at least twice. VOSviewer automatically placed keywords in 9 separate clusters and colour coded them accordingly.

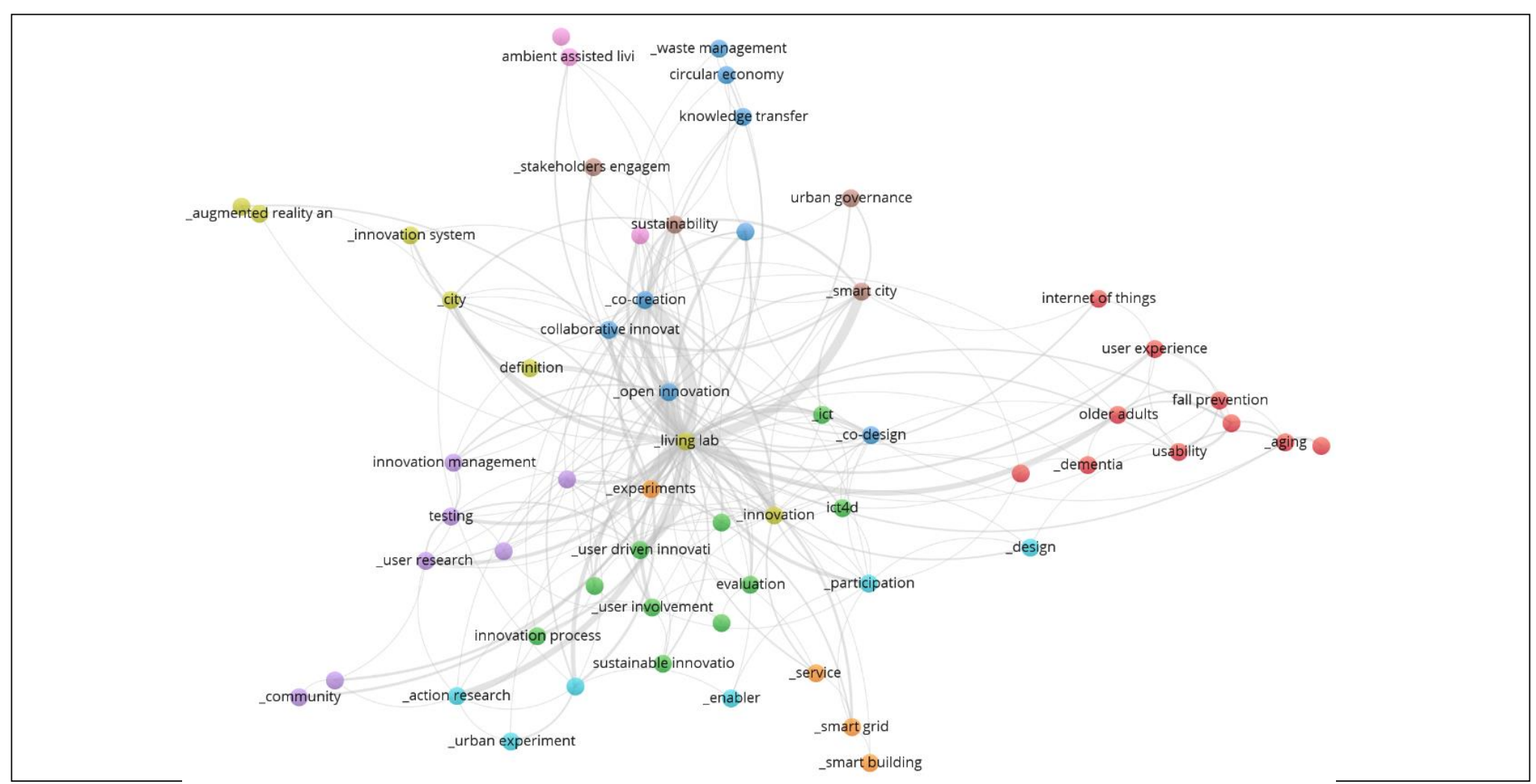

Figure 3 Author keyword co-occurrence 
While it is not surprising to observe the keyword "Living Lab" at the centre of the figure, it is interesting to observe very diverse clusters. On the right side, for example, the network identifies a group of keywords associated with health and aging. A brown group and a light blue cluster in the upper part of the figure, instead, capture concepts associated with sustainability and cities. From a more theoretical point of view, the LL concept is strongly associated with different forms of innovation, such as "open innovation", "co-creation" (light blue cluster), and "user driven innovation" (green cluster). The visualisation, on the one hand, confirms the presence of LL concepts in association with very diverse fields; on the other, it also shows how some of the theoretical roots of the LL approach are not considered by more applied and empirical studies.

To complement these analyses, co-citation analysis is used to investigate the theoretical foundations of a research domain. It has been successfully employed in fields associated with LLs, such as open innovation (Kovács, Van Looy and Cassiman, 2015; Randhawa, Wilden and Hohberger, 2016), business incubators (Hausberg and Korreck, 2020) and innovation in the context of strategic alliances (Di Guardo and Harrigan, 2012). Figure 4 presents the 41 most influential seminal contributions, which are cited at least 10 times by the 297 articles in Database B. Lines are visible when such sources are co-cited at least five times together. As a result, four clusters are identified and colour coded. Despite the clustering method being purely data driven and optimising the allocation of papers to different clusters, without necessarily reaching a perfect fit or a theoretically univocal solution, the identification of four subgroups facilitates a preliminary interpretation. The blue cluster is mainly related to open innovation literature. The red cluster is specifically focusing on LLs and innovation management, whereas the green cluster is concerned with LLs and sustainability challenges. The fourth cluster represents a single article highlighted in yellow. The article discusses LLs as an innovation milieu and an innovation approach (Bergvall-Kåreborn and Ståhlbröst, 2009).

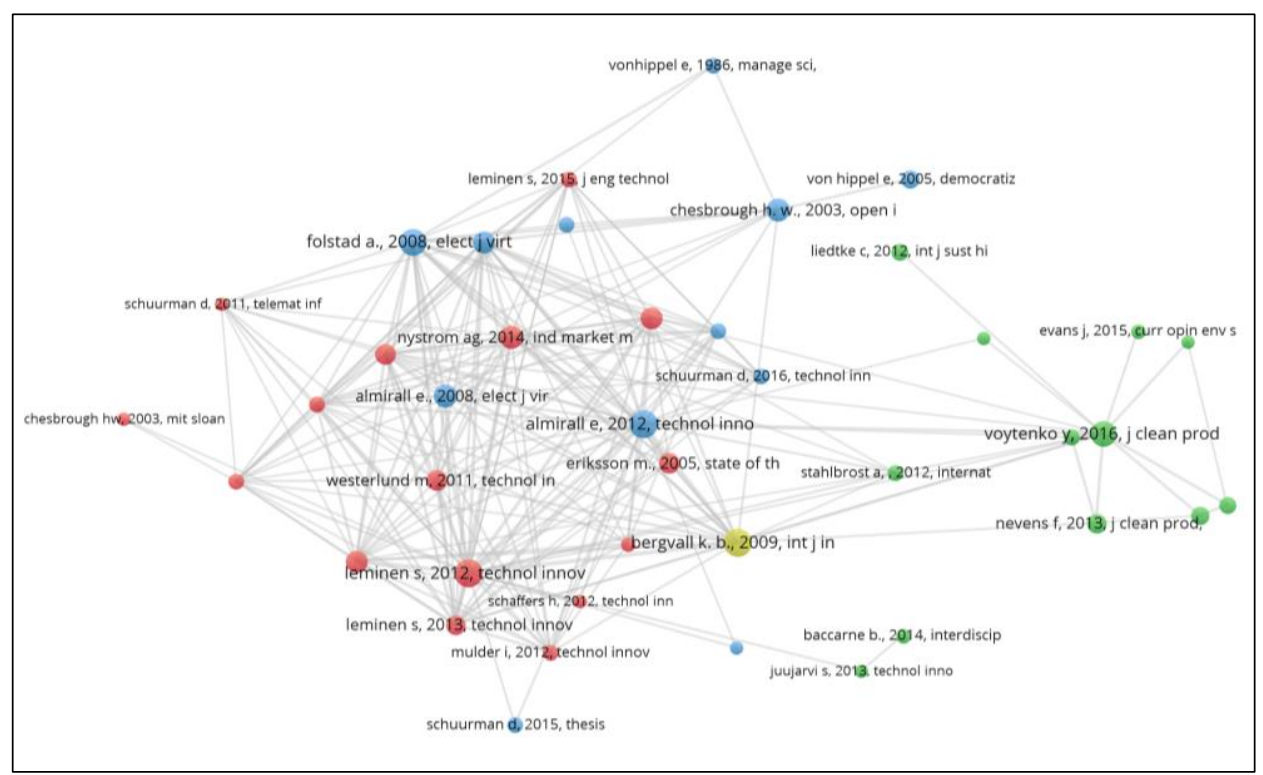

Figure 4 Most cited references 
The full list of the 41 seminal sources is provided in Table 4; the table confirms the very recent nature of LL research. Furthermore, it is interesting to observe that one of the most commonly cited reference is the widely known paper from Eisenhardt (1989) regarding the use of case study to build theories. This illustrates that extant LL studies tend to rely on qualitative approaches, showing the importance for the field to move towards broader generalisation of findings and propositions by using also other methodological approaches. Finally, two doctoral dissertations and one report are included in the list of the most cited references. This fact confirms the nascent and emergent state of the LL literature, together with its applied nature.

Table 4 References cited at least 10 times

References in alphabetical order

Almirall, E., \& Wareham, J. (2008). Living labs and open innovation: Roles and applicability. eJOV: The Electronic Journal for Virtual Organization \& Networks, 10.

Almirall, E., \& Wareham, J. (2011). Living Labs: arbiters of mid-and ground-level innovation. Technology Analysis \& Strategic Management, 23(1), 87-102.

Almirall, E., Lee, M., \& Wareham, J. (2012). Mapping living labs in the landscape of innovation methodologies. Technology Innovation Management Review, 2(9). 12-18

Baccarne, B., Mechant, P., Schuurman, D., Colpaert, P., \& De Marez, L. (2014). Urban sociotechnical innovations with and by citizens. Interdisciplinary studies journal, 3(4), 143-156.

Bergvall-Kåreborn, B., \& Ståhlbröst, A. (2009). Living Lab: an open and citizen-centric approach for innovation. International Journal of Innovation and Regional Development, 1(4), 356-370.

Bulkeley, H., \& Castán Broto, V. (2013). Government by experiment? Global cities and the governing of climate change. Transactions of the institute of British geographers, 38(3), 361375.

Bulkeley, H., Coenen, L., Frantzeskaki, N., Hartmann, C., Kronsell, A., Mai, L., Marvin, S., McCormick, K., van Steenbergen, F. \& Voytenko Palgan, Y. (2016). Urban living labs: governing urban sustainability transitions. Current Opinion in Environmental Sustainability, 22, 13-17.

Chesbrough, H. W. (2003a). Open innovation: The new imperative for creating and profiting from technology. Harvard Business Press.

Chesbrough, H. W. (2003b). The era of open innovation. MIT Sloan management Review, 44(3), 35-41.

Dell'Era, C., \& Landoni, P. (2014). Living Lab: A methodology between user-centred design and participatory design. Creativity and Innovation Management, 23(2), 137-154.

Dutilleul, B., Birrer, F. A., \& Mensink, W. (2010). Unpacking European Living Labs: Analysing Innovation's Social Dimensions. Central European journal of public policy, 4(1).

Eisenhardt, K. M. (1989). Building theories from case study research. Academy of Management Review, 14(4), 532-550.

Eriksson, M., Niitamo, V. P., \& Kulkki, S. (2005). State-of-the-art in utilizing Living Labs approach to user-centric ICT innovation-a European approach. Lulea: Center for Distancespanning Technology. Lulea University of Technology Sweden: Lulea.

Evans, J., \& Karvonen, A. (2014). 'Give me a laboratory and I will lower your carbon footprint!'-Urban laboratories and the governance of low-carbon futures. International Journal of Urban and Regional Research, 38(2), 413-430. 
Evans, J., Jones, R., Karvonen, A., Millard, L., \& Wendler, J. (2015). Living labs and coproduction: university campuses as platforms for sustainability science. Current Opinion in Environmental Sustainability, 16, 1-6.

Evans, J., Karvonen, A., \& Raven, R. (2016). The experimental city: New modes and prospects of urban transformation. In J. Evans, A. Karvonen, \& R. Raven (Eds.), The experimental city (pp. 1-12). Oxon and New York, NY: Routledge.

Følstad, A. (2008). Living Labs for Innovation and Development of Information and Communication Technology: A Literature Review. eJOV: The Electronic Journal for Virtual Organization \& Networks, 10.

Juujärvi, S., \& Pesso, K. (2013). Actor Roles in an Urban Living Lab: What Can We Learn from Suurpelto, Finland?. Technology Innovation Management Review, 3(11), 22-27.

Leminen, S. (2013). Coordination and participation in living lab networks. Technology Innovation Management Review, 3(11), 5-14.

Leminen, S. (2015). Living labs as open innovation networks-networks, roles and innovation outcomes. PhD thesis, Aalto University, Finland.

Leminen, S., \& Westerlund, M. (2012). Towards innovation in Living Labs networks. International Journal of Product Development, 17(1-2), 43-59.

Leminen, S., \& Westerlund, M. (2017). Categorization of innovation tools in living labs. Technology Innovation Management Review, 7(1), 15-25

Leminen, S., Nyström, A. G., \& Westerlund, M. (2015). A typology of creative consumers in living labs. Journal of Engineering and Technology Management, 37, 6-20.

Leminen, S., Westerlund, M., \& Nyström, A. G. (2012). Living Labs as Open-Innovation Networks. Technology Innovation Management Review, 2(9).

Leminen, S., Westerlund, M., \& Nyström, A. G. (2014). On becoming creative consumers-user roles in living labs networks. International Journal of Technology Marketing, 9(1), 33-52.

Liedtke, C., Welfens, M. J., Rohn, H., \& Nordmann, J. (2012). Living Lab: user-driven innovation for sustainability. International journal of sustainability in higher education.

Mulder, I. (2012). Living labbing the Rotterdam way: Co-creation as an enabler for urban innovation. Technology Innovation Management Review, 2(9), 39-43.

Nevens, F., Frantzeskaki, N., Gorissen, L., \& Loorbach, D. (2013). Urban Transition Labs: cocreating transformative action for sustainable cities. Journal of Cleaner Production, 50, 111122.

Nyström, A. G., Leminen, S., Westerlund, M., \& Kortelainen, M. (2014). Actor roles and role patterns influencing innovation in living labs. Industrial Marketing Management, 43(3), $483-$ 495.

Prahalad, C. K., \& Ramaswamy, V. (2000). Co-opting customer competence. Harvard business review, 78(1), 79-90.

Schaffers, H., \& Turkama, P. (2012). Living Labs for cross-border systemic innovation. Technology Innovation Management Review, 2(9), 25-30.

Schuurman, D. (2015) Bridging the gap between open and user innovation? Exploring the value of living labs as a means to structure user contribution and manage distributed innovation. $\mathrm{PhD}$ Thesis, Ghent University and Vrije Universiteit Brussel (VUB).

Schuurman, D., De Marez, L., \& Ballon, P. (2016). The impact of living lab methodology on open innovation contributions and outcomes. Technology Innovation Management Review, 6(1), 7-16.

Schuurman, D., De Moor, K., De Marez, L., \& Evens, T. (2011). A Living Lab research approach for mobile TV. Telematics and Informatics, 28(4), 271-282. 
Ståhlbröst, A. (2012). A set of key-principles to assess the impact of living labs. International Journal of Product Development, 17(1-2), 60-75.

Ståhlbröst, A. (2013). A living lab as a service: Creating value for micro-enterprises through collaboration and innovation. Technology Innovation Management Review, 3(11), 37-42.

Veeckman, C., Schuurman, D., Leminen, S., \& Westerlund, M. (2013). Linking living lab characteristics and their outcomes: Towards a conceptual framework. Technology Innovation Management Review, 3(12), 6-15.

von Hippel, E. (2005) Democratizing innovation: Users take center stage. Boston MA: MIT

Press

von Hippel, E. V (1986) Lead Users: A Source of Novel Product Concepts. Management Science, 32(7), 791-805

Voytenko, Y., McCormick, K., Evans, J., \& Schliwa, G. (2016). Urban living labs for sustainability and low carbon cities in Europe: Towards a research agenda. Journal of Cleaner Production, 123, 45-54.

Westerlund, M., \& Leminen, S. (2011). Managing the challenges of becoming an open innovation company: experiences from Living Labs. Technology Innovation Management Review, 1(1), 19-25.

\section{Discussion and Conclusion}

This study sheds light on the overall landscape of LL research and pinpoints potential areas of fragmentation and isolation in the field. In particular, our analysis of the structure and content of LL research maps the debate in the field during the past three decades. Findings of this study are connected with the emergence of the LL literature and include several contributions to research on LLs.

\section{Theoretical implications}

This study makes important theoretical contributions by improving our understanding of the intellectual streams and core concepts that constitute LL research, and by identifying opportunities to develop a future research agenda.

Firstly, the findings suggest that although the number of scholarly studies on LLs have been rapidly increasing during the past few years, research in the field remains fragmented across different disciplines. This discovery was particularly apparent upon examining the co-authorship network. The fragmentation can be seen as an opportunity for scholars interested in contributing to the field. There is plenty of room for ground-breaking LL research. For example, applying previously unused theoretical approaches and taking a cross-disciplinary perspective may help advancing the field and bringing LLs into mainstream innovation research. The global research community focused on innovation management, for instance, witnessed a flourishment of research after the ground-breaking foundations for the open innovation concept were established by Henry Chesbrough (2003). Paying more attention to LLs could open up a whole new research avenue within this domain, and foster not only the already mainstream open innovation research area, but also contribute to the debate about social and environmental sustainability. Furthermore, given the utility of LLs, they could find application in a variety of fields including, for example, entrepreneurship. In light of rapidly changing management and policy contexts, 
the use of LLs has also the potential to influence fundamental economic and social development addressing challenges faced by commercial firms, social services, emerging economies and sustainability goals (Tidd and Bessant, 2018).

Secondly, this study explored the co-occurrence of keywords in the LL field. Again, the keyword analysis showed the diversity of research in terms of domains and disciplines. However, at the same time, it helped to tap into emergent domains and research fields including, but not limited to, different forms of innovation (e.g. "open innovation" and "user innovation"), sustainability in the urban city context, and health and aging, thus offering multiple opportunities for future research. Our study corroborates and complements a thematic analysis based on automated content analysis tools on a single journal (cf. topic modelling analysis on LLs by Westerlund, Leminen and Rajahonka (2018)). Even if the methodologies are not fully comparable, similar concepts are detected through our analysis. The identification of specific contexts in which LLs are implemented highlights the applied nature of LL research, which is growing from empirical evidence and needs to be enriched from a more theoretical perspective.

The nascent state of LL literature is indeed confirmed by the results of our co-citation analysis. Several of the well accepted LL publications are part of special issues, which act as focal point to attract a conversation otherwise fragmented. Some special issues have been published with a clear focus on LLs, such as The Electronic Journal of Virtual Organizations and Networks (e.g. Almirall and Wareham, 2008; Følstad, 2008), Technology Innovation Management Review (e.g. Almirall et al., 2012; Mulder, 2012), and International Journal of Product Development (Leminen and Westerlund, 2012; Ståhlbröst, 2012). Many highly cited LL studies were also published in non-LL themed special issues focusing on a specific key concept. Examples of these include the multiplicity of stakeholders and networks in Industrial Marketing Management (Nyström et al., 2014) and the central role of users in Journal of Engineering and Technology Management (Leminen, Nyström and Westerlund, 2015).

Other highly cited references, instead, are used to position LLs with respect to more mature mainstream research areas, such as open innovation (cf. Chesbrough, 2003a; Chesbrough, 2003b) and user innovation (cf. von Hippel, 1986, 2005). For example, Nyström et al. (2014) use role theory to further conceptualise roles in LL networks, which they consider to be a specific form of open innovation networks. Such articles not only go "beyond LLs" but establish bridges between different academic disciplines and schools of thought. Similarly, many highly cited LL publications contribute to discussions on social and sustainability aspects in urban cities and regions (cf. Nevens et al., 2013; Evans and Karvonen, 2014; Evans et al., 2015; Evans, Karvonen and Raven, 2016; Voytenko et al., 2016).

Such insights were developed thanks to the novel application of bibliometric approaches to the LL field, which allows complementing other literature reviews in this domain.

\section{Managerial implications}

In addition to contributions to theory, this study offers several implications for business managers and innovation practitioners involved with or planning to lead LL activities. Keeping in mind that LLs offer a platform to advance collaborative innovation, our findings suggest that not only LLs are an increasingly popular innovation approach, but they have the potential to provide value to a multitude of stakeholders. LLs create 
opportunities for companies, non-commercial organisations, user communities and individuals to engage in innovating, co-creating, testing, and validating ideas, products, services, solutions and systems. Our study highlighted that LLs have been used to tackle challenges in different real-life contexts, such as information and communication technologies, health and welfare services, and smart city development, as well as sustainability challenges. Furthermore, LLs can be employed to solve many of today's social challenges (Nyström et al., 2014; Leminen et al., 2016). Current events such as the coronavirus pandemic stress the importance of open and collaborative approaches to innovation, making the use of LLs increasingly relevant for governments, companies, public organisations and individuals. Indeed, LLs provide opportunities to acquire, share and integrate external knowledge and expertise, which organisations and companies may otherwise not have. LLs enable companies to identify challenges and find solutions beyond their organisational boundaries. In other words, governmental and non-governmental bodies, businesses and non-profit organisations can benefit significantly from utilising LLs. Finally, this study provides a map to practitioners to investigate and learn from the application of LLs in diverse fields.

\section{Limitations and avenues for future research}

As always, there are limitations in each study. Firstly, this study does not include reports, conference papers, or books as part of its analysis. Some relevant domains or disciplines, as well as influential conference papers or book chapters may thus have been excluded from the analysis. Secondly, this study attempts to maximise the number of the analysed articles by combining different databases part of WoS. However, as not all information were consistently available across databases, some analysis could only be performed on a subset of the 411 articles. Thirdly, this study relies on WoS which has been selected also for its capacity to produce information in a more standardised format, which, however, is not completely free from inconsistencies. A manual process of disambiguation had to be carried out in order to ensure the consistency of cited references, authors' identification and keywords. However, we cannot fully exclude the possibility of some inconsistencies remaining in the database.

These limitations also spark suggestions for future LL research in an effort to move the LL field forward. One of the main findings of this study draws attention to the fact that LLs are profoundly linked to other fields and domains such as open innovation (cf. Chesbrough, 2003a; Chesbrough, 2003b), user innovation (cf. von Hippel, 1986, 2005), as well as social and sustainability challenges in urban cities and regions (cf. Nevens et al., 2013; Evans et al., 2015; Voytenko et al., 2016). Many LL studies have used popular qualitative methodologies such as case studies (Eisenhardt, 1989). That said, we call for more research applying a richer set of methods, including qualitative, quantitative, and mixed-methods, as well as artificial intelligence and machine learning based techniques to further analyse the extant body of literature on LLs, the variety of LLs and their activities, and the plurality of stakeholders. Finally, future research could replicate this study by analysing other innovation facilities, including but not limited to testbeds and pilot lines, so that to draw comparative insights and build a more integrated overview and understanding of the broader demonstration environment landscape. 


\section{References}

Abowd, G. D. (1999) 'Classroom 2000: An Experiment with the Instrumentation of a Living Educational Environment’, IBM Systems Journal, 38(4), pp. 508-530.

Almirall, E. et al. (2012) 'Mapping living labs in the landscape of innovation methodologies', Technology Innovation Management Review, 2(9), pp. 12-18.

Almirall, E. and Wareham, J. (2008) 'Living labs and open innovation: Roles and applicability’, The Electronic Journal for Virtual Organization and Networks, 10(3), pp. 21-46.

Autili, M. et al. (2019) 'A choreography-based and collaborative road mobility system for L'Aquila city', Future Internet, 11(6). doi: 10.3390/fi11060132.

Ballon, P., Van Hoed, M. and Schuurman, D. (2018) 'The effectiveness of involving users in digital innovation: Measuring the impact of living labs', Telematics and Informatics, 35(5), pp. 1201-1214. doi: 10.1016/j.tele.2018.02.003.

Ballon, P. and Schuurman, D. (2015) 'Living labs: concepts, tools and cases', Info, 17(4), pp. 1-11.

Belur, J. et al. (2018) 'Interrater Reliability in Systematic Review Methodology:

Exploring Variation in Coder Decision-Making', Sociological Methods and Research. doi: $10.1177 / 0049124118799372$.

Bergvall-Kåreborn, B. Ståhlbröst, A. (2009) 'Living Lab: an open and citizen-centric approach for innovation', International Journal of Innovation and Regional Development, 1(4), pp. 356-370.

Bergvall-Kåreborn, B., Holst, M. and Ståhlbröst, A. (2009) 'Concept design with a living lab approach', in Proceedings of the 42nd Annual Hawaii International Conference on System Sciences, HICSS, pp. 1-10.

Blain, H. et al. (2014) 'Living lab falls-MACVIA-LR: The falls prevention initiative of the european innovation partnership on active and healthy ageing (EIP on AHA) in Languedoc-Roussillon', European Geriatric Medicine, 5(6), pp. 416-425. doi: 10.1016/j.eurger.2014.07.010.

Borgatti, S. P., Everett, M. G. and Freeman, L. C. (2002) Ucinet for Windows: Software for social network analysis. Harvard, MA: Analytic Technologies.

Bousquet, J. et al. (2014) 'MACVIA-LR, Reference site of the European Innovation Partnership on Active and Healthy Ageing (EIP on AHA) in Languedoc Roussillon', European Geriatric Medicine, 5(6), pp. 406-415. doi: 10.1016/j.eurger.2014.07.013.

Bové, J. et al. (2005) 'Toxin-induced models of Parkinson's disease', NeuroRX, 2(3), pp. 484-494.

Chesbrough, H. (2003a) Open innovation: The new imperative for creating and profiting from technology. Boston, Massachusetts: Harvard Business School Press.

Chesbrough, H. (2003b) 'The Logic of Open Innovation: Managing Intellectual Property', California Management Review, 45(3), pp. 33-58.

Dahlander, L. and Gann, D. M. (2010) 'How open is innovation?', Research Policy. 
Elsevier B.V., 39(6), pp. 699-709. doi: 10.1016/j.respol.2010.01.013.

Dekker, R., Franco Contreras, J. and Meijer, A. (2019) 'The Living Lab as a Methodology for Public Administration Research a Systematic Literature Review of its Applications in the Social Sciences', International Journal of Public Administration. Taylor and Francis Inc., pp. 1-11. doi: 10.1080/01900692.2019.1668410.

Dotsika, F. and Watkins, A. (2017) 'Identifying potentially disruptive trends by means of keyword network analysis', Technological Forecasting and Social Change, 119, pp. 114127. doi: 10.1016/j.techfore.2017.03.020.

Dutilleul, B., Birrer, F. A. J. and Mensink, W. (2010) 'Unpacking european living labs: Analysing innovation's social dimensions', Central European Journal of Public Policy, 4(1), pp. 60-85.

van Eck, N. J. and Waltman, L. (2010) 'Software survey: VOSviewer, a computer program for bibliometric mapping', Scientometrics, 84(2), pp. 523-538. doi: 10.1007/s11192-009-0146-3.

Eisenhardt, K. M. (1989) 'Building theories from case study research', Academy of Management Review, 14(4), pp. 532-550.

Engels, F., Wentland, A. and Pfotenhauer, S. M. (2019) 'Testing future societies? Developing a framework for test beds and living labs as instruments of innovation governance', Research Policy. Elsevier, 48(9), p. 103826. doi: 10.1016/j.respol.2019.103826.

Evans, J. et al. (2015) 'Living labs and co-production: University campuses as platforms for sustainability science', Current Opinion in Environmental Sustainability. Elsevier B.V., 16, pp. 1-6. doi: 10.1016/j.cosust.2015.06.005.

Evans, J. and Karvonen, A. (2014) 'Give me a laboratory and I will lower your carbon footprint!'-Urban laboratories and the governance of low-carbon futures', International Journal of Urban and Regional Research, 38(2), pp. 413-430.

Evans, J., Karvonen, A. and Raven, R. (2016) 'The experimental city: New modes and prospects of urban transformation', in Evans, J., Karvonen, A., and Raven, R. (eds) The experimental city. Oxon and New York, NY: Routledge, pp. 1-12.

Følstad, A. (2008) 'Living Labs for innovation and development of information and communication technology: A literature review', The Electronic Journal of Virtual Organizations and Networks, 10(8), pp. 99-131.

Franz, Y. (2015) 'Designing social living labs in urban research', Info, 17(4), pp. 53-66.

Gascó, M. (2017) 'Living labs: Implementing open innovation in the public sector', Government Information Quarterly. Elsevier Inc., 34(1), pp. 90-98. doi:

10.1016/j.giq.2016.09.003

Gisev, N., Bell, J. S. and Chen, T. F. (2013) 'Interrater agreement and interrater reliability: Key concepts, approaches, and applications', Research in Social and Administrative Pharmacy. Elsevier Inc, 9(3), pp. 330-338. doi:

10.1016/j.sapharm.2012.04.004.

Di Guardo, M. C. and Harrigan, K. R. (2012) 'Mapping research on strategic alliances 
and innovation: a co-citation analysis', The Journal of Technology Transfer, 37(6), pp. 789-811.

Hartmann, E. (2014) 'The fetish of global competition', Capital and Class, 38(1), pp. 184-196. doi: 10.1177/0309816813514210.

Hausberg, J. P. and Korreck, S. (2020) 'Business incubators and accelerators: a cocitation analysis-based, systematic literature review', Journal of Technology Transfer. Springer US, 45(1), pp. 151-176. doi: 10.1007/s10961-018-9651-y.

von Hippel, E. (1986) 'Lead Users: A Source of Novel Product Concepts', Management Science, 32(7), pp. 791-805.

Von Hippel, E. (2005) Democratizing innovation. Cambridge, MA: MIT Press.

Hossain, M., Leminen, S. and Westerlund, M. (2019) 'A systematic review of living lab literature', Journal of Cleaner Production, 213, pp. 976-988. doi: 10.1016/j.jclepro.2018.12.257.

Huang, M. H. and Chang, Y. W. (2011) 'A study of interdisciplinarity in information science: using direct citation and co-authorship analysis', Journal of Information Science, 37(4), pp. 369-378.

Huisman, M. and van Duijn, M. A. (2011) 'A reader's guide to SNA software', in Scott, J. and Carrington, P. J. (eds) The SAGE handbook of social network analysis. SAGE publications, pp. 578-600.

Knight, T. (1749) 'Reflections upon Catholicons, or Universal Medicines', Reflections upon Catholicons, or Universal Medicines, (Printed for T. Osborne in Gray’s-Inn.).

Kovács, A., Van Looy, B. and Cassiman, B. (2015) 'Exploring the scope of open innovation: a bibliometric review of a decade of research', Scientometrics, 104(3), pp. 951-983. doi: 10.1007/s11192-015-1628-0.

Leminen, S. et al. (2016) 'The effect of network structure on radical innovation in living labs', Journal of Business \& Industrial Marketing, 31(6), pp. 743-757. doi: 10.1108/JBIM-10-2012-0179.

Leminen, S., Nyström, A. G. and Westerlund, M. (2015) 'A typology of creative consumers in living labs', Journal of Engineering and Technology Management, 37, pp. 6-20. doi: 10.1016/j.jengtecman.2015.08.008.

Leminen, S., Nyström, A. G. and Westerlund, M. (2019) 'Change processes in open innovation networks - Exploring living labs’, Industrial Marketing Management. Elsevier, (January), pp. 1-18. doi: 10.1016/j.indmarman.2019.01.013.

Leminen, S., Rajahonka, M. and Westerlund, M. (2017) 'Towards third-generation living lab networks in cities', Technology Innovation Management Review, 7(11), pp. 21-35.

Leminen, S. and Westerlund, M. (2012) 'Towards innovation in living labs networks', International Journal of Product Development, 17(1/2), p. 43.

Leminen, S. and Westerlund, M. (2016) 'A framework for understanding the different research avenues of living labs', International Journal of Technology Marketing, 11(4), pp. 399-420. 
Leminen, S. and Westerlund, M. (2019) 'Living labs: From scattered initiatives to a global movement', Creativity and Innovation Management, 28(2), pp. 250-264. doi: 10.1111/caim.12310.

Leminen, S., Westerlund, M. and Nyström, A. G. (2012) 'Living labs as open-innovation networks', Technology Innovation Management Review, 2(September), pp. 6-11.

McLoughlin, S. et al. (2018) 'Living Labs: A Bibliometric Analysis', in 51st Hawaii International Conference on System Sciences, pp. 4463-4472. doi: 10.24251/hicss.2018.563.

Mian, S., Lamine, W. and Fayolle, A. (2016) 'Technology Business Incubation: An overview of the state of knowledge', Technovation. Elsevier, 50-51(Special Issue), pp. 1-12. doi: 10.1016/j.technovation.2016.02.005.

Mitchell, W. J. (2003) Me++: the cyborg self and the networked city. Cambridge, MA: MIT Press.

Mulder, I. (2012) 'Mulder, I., 2012. Living labbing the Rotterdam way: Co-creation as an enabler for urban innovation', Technology Innovation Management Review, 2(9), pp. 3943.

Nevens, F. et al. (2013) 'Urban Transition Labs: Co-creating transformative action for sustainable cities', Journal of Cleaner Production. Elsevier Ltd, 50, pp. 111-122. doi: 10.1016/j.jclepro.2012.12.001.

Nyström, A. G. et al. (2014) 'Actor roles and role patterns influencing innovation in living labs', Industrial Marketing Management, 43(3), pp. 483-495.

Pascu, C. and van Lieshout, M. (2009) 'User-led, citizen innovation at the interface of services', Info, 11(6), pp. 82-96.

Randhawa, K., Wilden, R. and Hohberger, J. (2016) 'A bibliometric review of open innovation: Setting a research agenda', Journal of Product Innovation Management, 33(6), pp. 750-772.

Rodrigues, M. and Franco, M. (2018) 'Importance of living labs in urban Entrepreneurship: A Portuguese case study', Journal of Cleaner Production, (180), pp. 780-789.

Sanders, E. B.-N. and Stappers, P. J. (2008) 'Co-creation and the new landscapes of design', CoDesign, 4(1), pp. 5-18.

Schuurman, D. et al. (2011) 'A living lab research approach for mobile TV', Telematics and Informatics, 28(4), pp. 271-282.

Schuurman, Dimitri, De Marez, L. and Ballon, P. (2015) 'Living Labs: a systematic literature review', Open Living Lab Days 2015.

Schuurman, D., De Marez, L. and Ballon, P. (2015) 'Living Labs: a Systematic Literature Review', in Open Living Lab Days 2015.

De Silva, M. and Wright, M. (2019) 'Entrepreneurial co-creation: Societal impact through open innovation', $R$ and D Management, 49(3), pp. 318-342. doi:

10.1111/radm.12362. 
Ståhlbröst, A. (2012) 'A set of key principles to assess the impact of living labs', International Journal of Product Development, 17(1/2), p. 60.

Di Stefano, G., Gambardella, A. and Verona, G. (2012) 'Technology push and demand pull perspectives in innovation studies: Current findings and future research directions', Research Policy, 41(8), pp. 1283-1295. doi: 10.1016/j.respol.2012.03.021.

Di Stefano, G., Peteraf, M. and Verona, G. (2010) 'Dynamic capabilities deconstructed: A bibliographic investigation into the origins, development, and future directions of the research domain', Industrial and corporate change, 19(4), pp. 1187-1204. doi: 10.1093/icc/dtq027.

Tidd, J. and Bessant, J. (2018) 'Innovation management challenges: From fads to fundamentals', International Journal of Innovation Management, 22(5), pp. 1-13.

Voytenko, Y. et al. (2016) 'Urban living labs for sustainability and low carbon cities in Europe: Towards a research agenda', Journal of Cleaner Production, 123, pp. 45-54.

Wasserman, S. and Faust, K. (1994) Social network analysis: Methods and applications. Vol. 8. Cambridge university press.

Westerlund, M. and Leminen, S. (2011) 'Managing the challenges of becoming an open innovation company: Experiences from living labs', Technology Innovation Management Review, (October), pp. 19-25.

Westerlund, M., Leminen, S. and Rajahonka, M. (2018) 'A Topic Modelling Analysis of Living Labs Research', Technology Innovation Management Review, 8(7), pp. 40-51. doi: 10.22215/timreview/1170.

Williams, R., Stewart, J. and Slack, R. (2005) Social learning in technological innovation: Experimenting with information and communication technologies. Edward Elgar Publishing. 